\title{
Antecedents and self-induction of active-break south Asian monsoon unraveled by satellites
}

\author{
Bin Wang, ${ }^{1}$ Peter J. Webster, ${ }^{2}$ and Haiyan Teng ${ }^{1}$ \\ Received 13 July 2004; revised 22 November 2004; accepted 2 December 2004; published 18 February 2005.
}

[1] Understanding the origin and perpetuation of the monsoon cycle has eluded scientists for decades. Using a suite of unprecedented satellite measurements, we show that the antecedents of the active/break monsoon emerge in the western equatorial Indian Ocean (EIO). The initiation of a new rainy phase in the western EIO is preceded by in situ surface wind convergence and central EIO warming, both are induced by the subdued condition over the eastern EIO set up in the previous cycle. Thus, a selfinduction mechanism appears to be operating in maintenance of the Indian monsoon intraseasonal oscillation. The finding here offers a focus for prediction of the active/break Indian monsoon with potential predictability about four weeks in advance. Citation: Wang, B., P. J. Webster, and H. Teng (2005), Antecedents and self-induction of active-break south Asian monsoon unraveled by satellites, Geophys. Res. Lett., 32, L04704, doi:10.1029/2004GL020996.

\section{Introduction}

[2] The Indian summer monsoon exhibits prominent 3040 day fluctuations with "active" periods of heavy rain interrupted by dry "breaks" [Gadgil, 2003; Krishnamurti and Bhalme, 1976]. The circulation anomalies associated with active/break monsoons cover up the entire Indian Ocean and influence remote tropics and North Pacific Ocean [Webster et al., 1998]. A prolonged dry/rainy period will result in severe drought/flooding, which have profound influences on South Asian water cycle, agriculture and societal activity of over one billion people [Gadgil, 2003]. However, the state-of-the-art atmospheric general circulation models have great difficulty in simulating the monsoon cycle [Waliser et al., 2003].

[3] Previous studies have established that the active/break monsoons are triggered by organized northward propagation of heavy precipitating or cloud-free zones from the equatorial region towards the continental land mass [e.g., Yasunari, 1979; Sikka and Gadgil, 1980]. However, a remaining question of some consequence is where and how the convective anomalies that bring about active and break periods of monsoon are generated. There is some support for the idea that the upper-level divergent waves associated with the Madden and Julian [1971] oscillation (MJO) that circumnavigate the globe, could re-initiate

\footnotetext{
${ }^{1}$ Department of Meteorology and International Pacific Research Center, University of Hawaii at Manoa, Honolulu, Hawaii, USA.

${ }^{2}$ School of Earth and Atmospheric Science and School of Civil and Environmental Engineering, Georgia Institute of Technology, Atlanta, Georgia, USA.

Copyright 2005 by the American Geophysical Union. 0094-8276/05/2004GL020996\$05.00
}

convective anomalies over the Indian Ocean [e.g., Lorenc, 1984; Lau and Chan, 1986]. However, Salby and Hendon [1994] show that the decorrelation time of the MJO is less than 1 cycle. Hence, one event tends not to follow another. During boreal summer the equatorial eastward propagating MJO weakens substantially [Hendon and Salby, 1994] and some northward propagating episodes are independent of the MJO [Wang and Rui, 1990]; whether the circumnavigation of these upper tropospheric divergence waves can re-initiate convection over the Indian Ocean remains to be reexamined.

[4] Previous observational data and techniques were unable to detect the genesis process over the ocean, leaving it as a controversial issue in understanding the monsoon weather and climate. Here we take advantage of a suite of unprecedented satellite data to unravel the genesis process and pinpoint the mechanism for maintenance of monsoon cycle. The data we used are a suite of satellite measurements for precipitation rate, surface winds, SST, and cloud liquid water. One distinct advantage of the Tropical Rainfall Measuring Mission (TRMM) is the onboard TRMM Microwave Imager (TMI). TMI can measure a variety of parameters in the presence of cloud [Wentz and Schabel, 2000], providing reliable measurements of SST, precipitation, and cloud liquid water. The surface winds and convergence are derived from QuikSCAT scatterometer [Freilich and Dunbar, 1999]. The outgoing longwave radiation data and the general circulation model reanalysis dataset available from the European Centre for Mediumrange Weather Forecast (ECMWF) are used only as a complement reference to satellite data for the study.

[5] Figure 1 shows time series of daily precipitation rate averaged over the eastern $\operatorname{EIO}\left(5^{\circ} \mathrm{S}-5^{\circ} \mathrm{N}, 75^{\circ}-100^{\circ} \mathrm{E}\right)$ and the seas adjacent to Indian subcontinent $\left(15^{\circ}-25^{\circ} \mathrm{N}, 70^{\circ}-\right.$ $\left.95^{\circ} \mathrm{E}\right)$. The $20-50$ day oscillations in the eastern EIO rainfall is notably about $180^{\circ}$ out of phase with that over the South Asian (SA) region $(10-25 \mathrm{~N}, 70-100 \mathrm{E})$ (figure not shown). Fluctuations with a dominant period of 20-50 days account for majority of the total variance in the time series (The ratio in square root of variance between the 20-50 day filtered and daily time series is $60 \%, 74 \%$, and $74 \%$ for 2000,2001 , and 2003, respectively). From 2000 through 2002, each summer experienced four cycles from mid-May to midSeptember. This allows a total of 12 events for the construction of a composite to describe the mean behavior of a monsoon ISO.

[6] Since the periods of individual ISO cycles are irregular, ranging from 25 to 43 days (Figure 1), the method used to construct the composite life cycle was based on eight consecutive phases in each of the 12 cycles shown in Figure 1. Phases 1, 3, 5, and 7 correspond, respectively, to the times when the rainfall anomalies in the eastern EIO are at a minimum, negative-turning-to-positive, a maximum, 


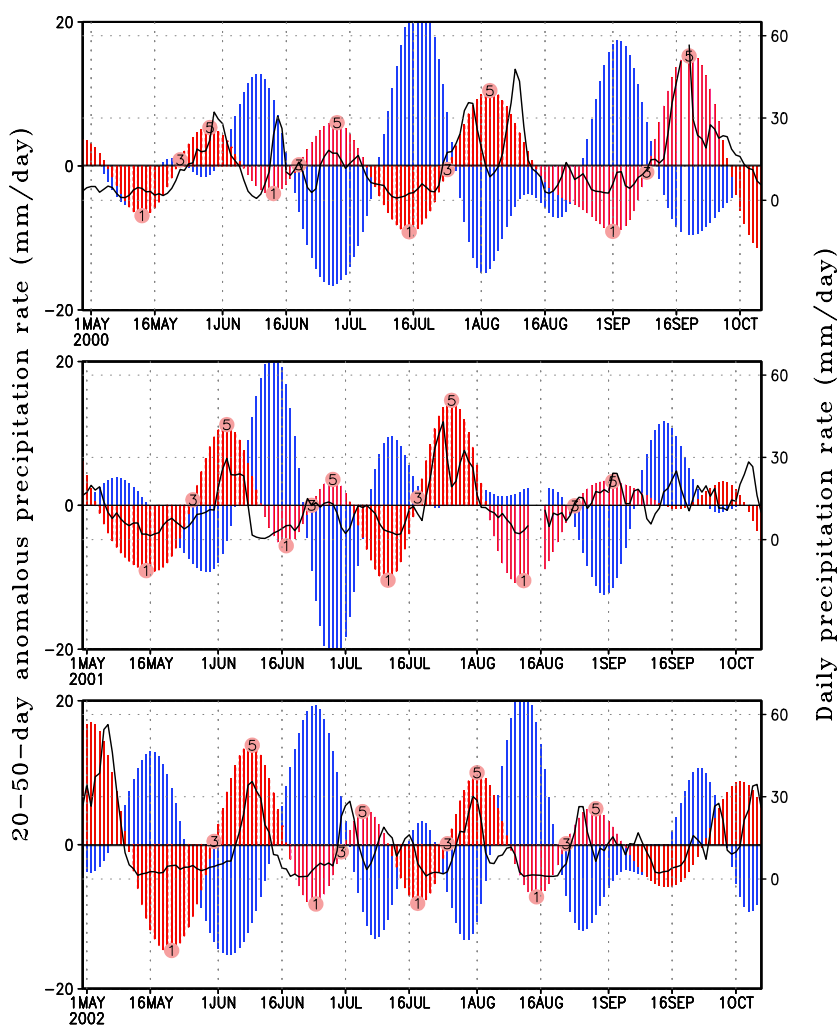

Figure 1. Time series of daily rainfall rate derived from TMI data. The black curve represents the three-day running mean daily precipitation rate averaged in the $\operatorname{EIO}\left(5^{\circ} \mathrm{S}-5^{\circ} \mathrm{N}\right.$, $\left.75^{\circ}-100^{\circ} \mathrm{E}\right)$. The red and blue bars denote the $20-50$ day anomalous precipitation rates in the EIO and in the Bay of Bengal $\left(15^{\circ} \mathrm{N}-25^{\circ} \mathrm{N}, 70^{\circ}-95^{\circ} \mathrm{E}\right.$ excluding land area), respectively. The circled numbers 1,3 , and 5 mark the timing of Phase 1,3 , and 5 for each oscillation cycle that are selected for the composite analysis.

and positive-turning-to-negative. Because of the out-ofphase relationship between the eastern EIO and India, Phase 1 and 5 are referred to the peak active (wet) and break (drought) phase of the SA monsoon, respectively. The average period of the 12 cycles used in composite is 33 days; thus the mean interval between two adjacent phases is about 4 days. Statistical analysis using the Student- $t$ test showed that the magnitude of anomalous rainfall rate exceeding $2 \mathrm{~mm} \mathrm{day}^{-1}$ and the magnitude of anomalous SST greater than $0.1{ }^{\circ} \mathrm{C}$ in the composite maps shown in Figure 2 are statistically significant at the $90 \%$ confidence level.

\section{Antecedents and Initiation of the Active/Break Indian Summer Monsoon}

[7] Figure 2 shows the averaged life cycle of the monsoon ISO. Phase 1 is characterized by a minimum rainfall in the eastern EIO and a peak wet monsoon over northern Bay of Bengal. About 4 days later (Phase 2), the dry anomalies move eastward and organized positive rainfall anomalies emerge in the western EIO between $60^{\circ} \mathrm{E}$ and $70^{\circ} \mathrm{E}$. These anomalies are the first sign of the next spell of monsoon rain. In Phase 3 the enhanced rainfall expand eastward along $5^{\circ} \mathrm{S}$, the climatological equatorial convergence zone. This con- vective anomaly then develops into a heavy precipitation region that is symmetric about the equator (Phase 4). Rainfall in the eastern EIO peaks during Phase 5, while the monsoon over SA undergoes a peak break phase. The enhanced convection significantly weakens as it passes over Sumatra. This weakening may result partly from topographic blocking that deteriorates the organized planetary boundary layer divergence and partly from the strong diurnal cycle in convection that, in turn, prohibits the accumulation of convective energy necessary for sustaining the ISO. Note that when the equatorial convection weakens, the wet region branches poleward, transforming into a $\mathrm{V}$-shaped rain band and tailing the main center of the equatorial convection in Phase 6. The V-shaped rain band is highly asymmetric about the equator. This asymmetry owes its origin primarily to the asymmetries in the vertical easterly shear (the upward decrease of the monsoon westerlies) and the SST distribution. A strong easterly vertical shear favors developing westward propagating Rossby waves and deep convections in the Northern Hemisphere [Wang and Xie, 1996]. This observation has allowed a new interpretation about the westward and poleward tilted rainband, which were found in previous statistical analyses of other datasets [Ferranti et al., 1997]. This titled rain band may form as a result of the Rossby wave emanation from the equatorial convection

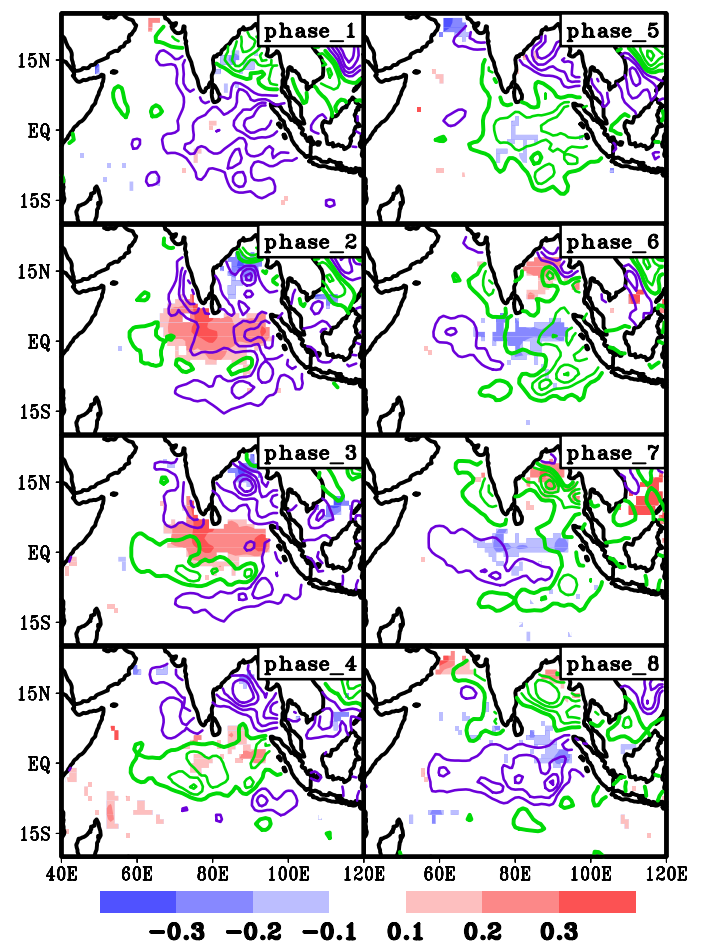

Figure 2. Composite life cycle of the SA summer monsoon 20-50 day oscillation. The contours of green (lavender) are positive (negative) precipitation anomalies starting from $2 \mathrm{~mm}$ day $^{-1}\left(-2 \mathrm{~mm}\right.$ day $\left.^{-1}\right)$ with a contour interval of $3 \mathrm{~mm}^{-1 a y}{ }^{-1}$. The thick green contour outlines the major positive precipitation anomalies. The color shading represents SST anomalies in units of ${ }^{\circ} \mathrm{C}$. The magnitude of anomalous rainfall rate exceeding $2 \mathrm{~mm}$ day $^{-1}$ and anomalous SST greater than $0.1^{\circ} \mathrm{C}$ are statistically significant at the $90 \%$ confidence level. 


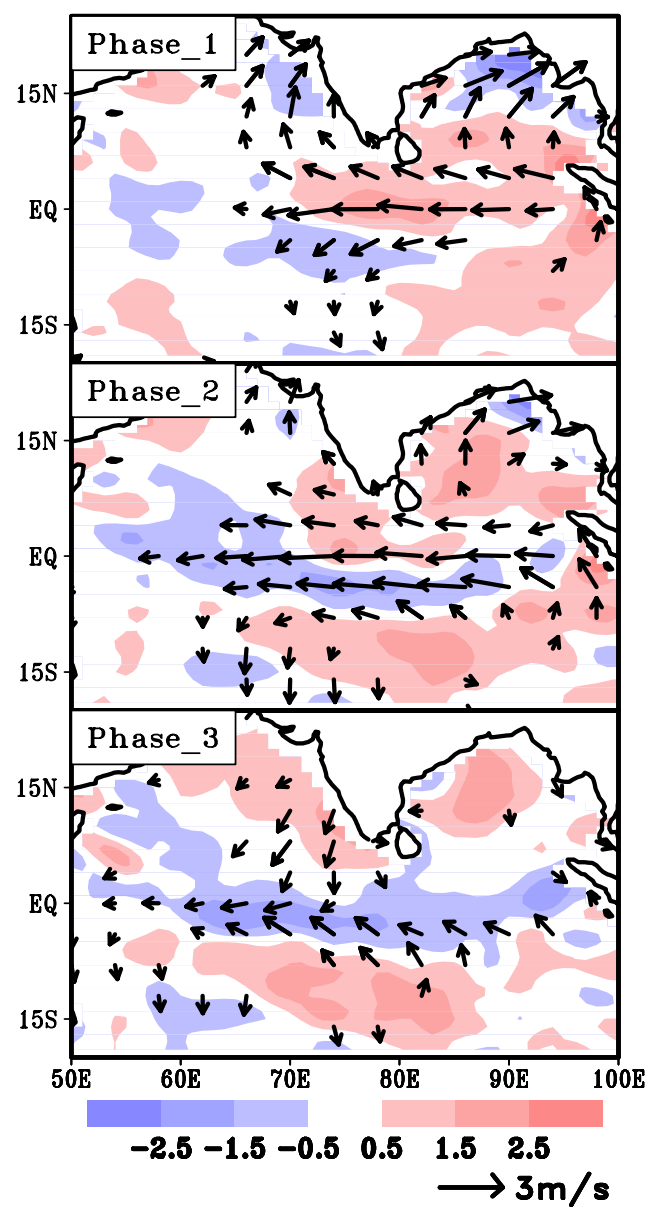

Figure 3. Composite genesis process (Phase 1, 2, and 3). Arrows and color shading represent 20-50 day anomalies of surface winds and divergence (in units of $10^{-6} \mathrm{~s}^{-1}$ ), respectively. Only the wind anomalies that are significant above the $90 \%$ confidence level are shown.

[Wang and Xie, 1997; Kemball-Cook and Wang, 2001; Lawrence and Webster, 2001]. Concurrent with this poleward bifurcation of rainband, suppressed convection restarts in the western EIO $\left(60^{\circ}-70^{\circ} \mathrm{E}\right)$. The life cycle continues with the northward and eastward propagation of the enhanced rain band, causing an active period in the Indian monsoon during Phases 7-8.

[8] To clarify the processes that create the initial convective anomalies, here we focus on the Phase 1-3. During Phase 1 the eastern EIO suppressed convection stimulates westward propagating descending Rossby waves [Gill, 1980], resulting in the twin surface anticyclones and equatorial easterly anomalies in the eastern-central Indian Ocean (Figure 3, Phase 1). The decreasing westward wind speed along the equator favors wind convergence in the western basin. Note that the occurrence of the surface convergence leads local rainfall anomaly by one phase (about four days). Because the heavy rains over India induce large-scale sinking motion (Figure 4, Phase 1) that dominates the $\mathrm{EIO}$, the surface convergence in the western EIO in this phase does not lead to organized convection immediately. However, it permits a moistening of the boundary layer, increasing the convective energy of the source air in the boundary layer and modifying the vertical stratification so that convection can occur again. Therefore, Phase 1 is a period during which the atmosphere is preconditioned for the next cycle. The finding here for the boreal summer ISO differs from the previous hypothesis of convective energy "recharge" process for MJO [Blade and Hartmann, 1993] in that the preconditioning is driven by the surface wind convergence.

[9] During Phase 2, the surface moisture convergence increases rapidly in the western and central EIO due to westward decrease of zonal equatorial wind and the confluence of equatorward winds associated with the southern Indian Ocean anticyclone that had moved westward from Phase 1 to Phase 2 (Figure 3, Phase 2). The organized precipitation anomalies emerge in the western EIO (Figure 2, Phase 2). During Phase 3, the twin anticyclones further extend and move into the Arabian Sea and the southwest Indian Ocean, respectively, due to Rossby wave propagation (Figure 3, Phase 3). The equatorward flows in the eastern part of the twin anticyclones reinforce moisture convergence in the central EIO and the convection. The enhanced convection further draws surface moisture convergence into it. Thus the precipitating clouds grow and expand into organized deep convection as corroborated by significantly more rainfall (Figure 2).

[10] Local atmosphere-ocean interaction may also favor for the genesis process. When the atmosphere over the central EIO is dry (Phase 7-8), the downward solar radiation increases because there are fewer clouds, while

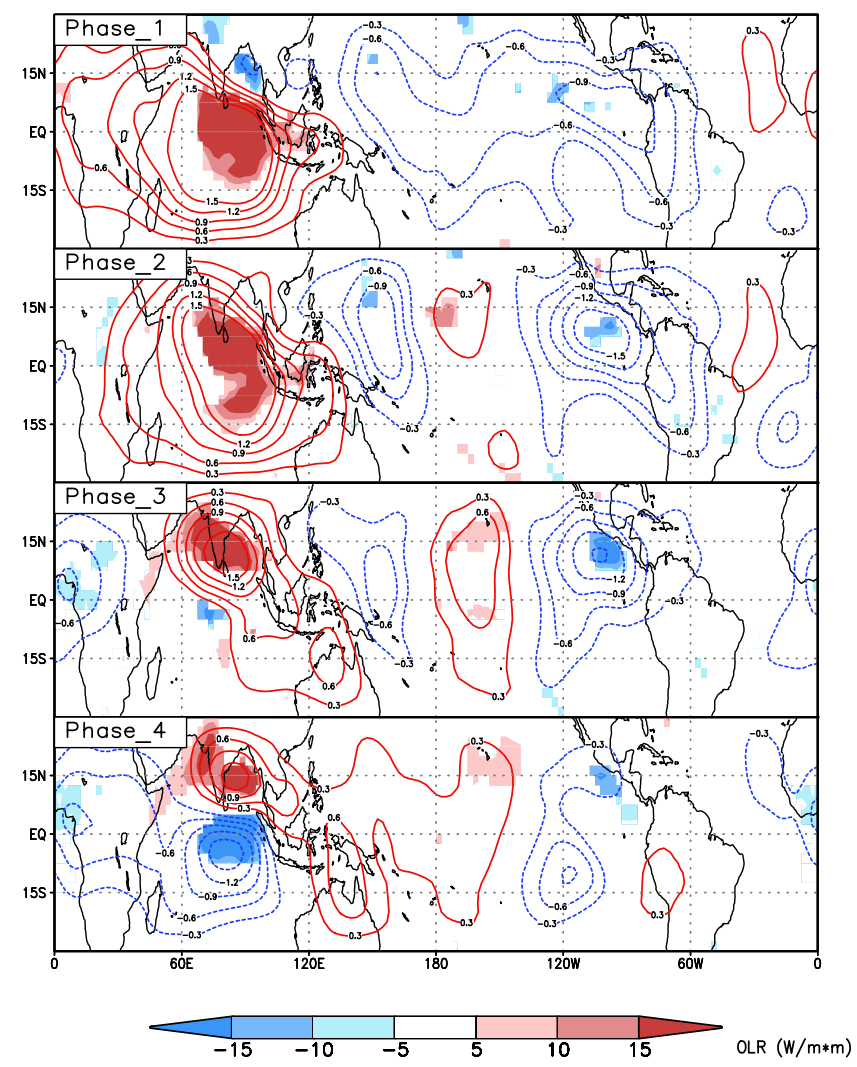

Figure 4. Composite anomalous $200 \mathrm{hPa}$ velocity potential (contour interval $10^{-6}$ ) and outgoing longwave radiation (shading, in units of $\mathrm{Wm}^{-2}$ ) from Phase 1 to 4 . The red (blue) contours represent positive (negative) velocity potential computed using ECMWF reanalysis data. 
the heat loss resulting from evaporation and entrainment cooling decreases because the wind speeds decrease. These arguments are consistent with the previous findings in analysis of the boreal summer ISO [Kemball-Cook and Wang, 2001; Vecchi and Harrison, 2002; Webster et al., 2002; Fu et al., 2003]. These features conspire to produce a warming of the sea surface about 8 days later in Phase 1-2 (Figure 2). On the other hand, the sea surface warming occurring during the Phase 1-2 may enhance energy flux into the atmospheric boundary layer, which builds up convective available potential energy for organized deep convection. In addition, the surface-warming-induced sensible heat flux tends to warm the air above, lowering the surface pressure. The lower surface pressure in turn enhances the boundary layer moisture convergence and promotes organized deep convection. Thus, local air-sea interaction may contribute to reinitiating of a new rainy phase.

\section{Conclusion and Discussion}

[11] The life cycle and genesis process revealed by satellite observations suggest a self-induction mechanism for the maintenance of the monsoon ISO. Both the surface wind convergence in the western-central basin and the ocean surface warming in the central basin, which are critical for breeding a new convective cycle, are induced by the anomalous conditions occurring during the peak phase of the previous cycle. This finding contrasts the notion that the circumnavigation of the upper tropospheric divergence waves associated with the MJO re-initiates convective anomalies over the Indian Ocean.

[12] The composite evolution of OLR and $200 \mathrm{hPa}$ velocity potential anomalies (Figure 4) shows that during the re-initiation of new convective anomalies, the EIO is under control of large-scale upper-level convergence and subsidence. Once deep convection starts in the central EIO, negative OLR anomaly develops locally; upper-level divergence then occurs later as a result of deep convection rather than its cause (Figure 4, Phases 3 and 4), confirming that the initiation of the ISO convection in the western EIO is primarily a local process within the SA monsoon system.

[13] Satellite measurements pinpoint the origin of the monsoon ISO and provide a comprehensive, fine-resolution picture of the ISO's life cycle. The results here offer some benchmark features for both the operational models and seasonal prediction models to validate their performance on the monsoon ISO. Surface convergence in the western EIO is noted about one month before heavy monsoon rain returns over India. This timing offers a focus for the prediction of the active or break Indian monsoon with potential predictability about four weeks ahead. To better understand air-sea interaction processes and their role in initiating and sustaining the boreal summer ISO, further collaborated meteorological and oceanographical observations are needed. In order to test the mechanisms advanced here, in situ field observations of the cloud formation and development are recommended.
[14] Acknowledgments. Bin Wang and Peter Webster acknowledge the support by the Climate Dynamics Program of the NSF. This is the School of Ocean and Earth Science and technology publication number 6538 and International Pacific Research center publication No 310.

\section{References}

Blade, I., and D. L. Hartmann (1993), Tropical intraseasonal oscillations in a simple nonlinear model, J. Atmos. Sci., 50, 2922-2939.

Ferranti, L., J. M. Slingo, T. N. Palmer, and B. J. Hoskins (1997), Relations between interannual and intraseasonal monsoon variability as diagnosed from AMIP integrations, Q. J. R. Meteorol. Soc., 123, 1323-1357.

Freilich, M. H., and R. S. Dunbar (1999), The accuracy of the NSCAT 1 vector winds: Comparisons with National Data Buoy Center buoys, J. Geophys. Res., 104, 11,231-11,246.

Fu, X., B. Wang, T. Li, and J. P. McCreary (2003), Coupling between northward-propagating, intraseasonal oscillations and sea surface temperature in the Indian Ocean, J. Atmos. Sci., 60, 1733-1753.

Gadgil, S. (2003), The Indian monsoon and its variability, Annu. Rev. Earth Planet. Sci., 31, 429-467.

Gill, A. E. (1980), Some simple solutions for heat-induced tropical circulations, Q. J. R. Meteorol. Soc., 106, 447-462.

Hendon, H. H., and M. L. Salby (1994), The life cycle of the MaddenJulian oscillation, J. Atmos. Sci., 51, 2225-2237.

Kemball-Cook, S., and B. Wang (2001), Equatorial waves and air-sea interaction in the boreal summer intraseasonal oscillation, J. Clim., 14, $2923-$ 2942.

Krishnamurti, T. N., and H. N. Bhalme (1976), Oscillations of a monsoon system. Part I: Observational aspects, J. Atmos. Sci., 33, 1937-1954.

Lau, K. M., and P. H. Chan (1986), Aspects of the 40-50 day oscillation during northern summer as inferred from OLR, Mon. Weather Rev., 114, $1354-1367$

Lawrence, D. M., and P. J. Webster (2001), Interannual variations of the intraseasonal oscillation in the south Asia summer monsoon region, J. Clim., 14, 2910-2922.

Lorenc, A. C. (1984), Evolution of planetary-scale 200-mb divergent flow during the FGGE year, Q. J. R. Meteorol. Soc., 110, 427-441.

Madden, R. A., and P. R. Julian (1971), Description of a 40-50 day oscillation in the zonal wind in the tropical Pacific, J. Atmos. Sci., 28, $702-708$.

Salby, M. L., and H. H. Hendon (1994), Intraseasonal behavior of clouds, temperature, and motion in the tropics, J. Atmos. Sci., 51, 2207-2224.

Sikka, D. R., and S. Gadgil (1980), On the maximum cloud zone and the ITCZ over Indian longitudes during the southwest monsoon, Mon. Weather Rev., 108, 1840-1853.

Vecchi, G., and D. E. Harrison (2002), Monsoon breaks and sub-seasonal sea surface temperature variability in the Bay of Bengal, J. Clim., 15, $1485-1493$.

Waliser, D. E., et al. (2003), AGCM simulations of intraseasonal variability associated with the Asian summer monsoon, Clim. Dyn., 21, 423446.

Wang, B., and H. Rui (1990), Synoptic climatology of transient tropical intraseasonal convection anomalies: 1975-1985, Meteorol. Atmos. Phys., $44,43-61$

Wang, B., and X. Xie (1996), Low-frequency equatorial waves in vertically shear flow. Part I: Stable waves, J. Atmos. Sci., 53, 449-467.

Wang, B., and X. Xie (1997), A model for the boreal summer intraseasonal oscillation, J. Atmos. Sci., 54, 72-86.

Webster, P. J., V. O. Magana, T. N. Palmer, J. Shukla, R. A. Tomas, M. Yanai, and T. Yasunari (1998), Monsoon: Processes, predictability, and the prospects for prediction, J. Geophys. Res., 103, 14,451-14,510.

Webster, P. J., et al. (2002), The JASMINE pilot study, Bull. Am. Meteorol. Soc., 83, 1603-1629.

Wentz, F. J., and M. Schabel (2000), Precise climate monitoring using complementary satellite data sets, Nature, 403, 414-416.

Yasunari, T. (1979), Cloudiness fluctuations associated with the Northern Hemisphere summer monsoon, J. Meteorol. Soc. Jpn., 57, 227-242.

H. Teng and B. Wang, Department of Meteorology, University of Hawaii at Manoa, Honolulu, HI 96822, USA. (bwang@soest.hawaii.ed)

P. J. Webster, School of Earth and Atmospheric Science, Georgia Institute of Technology, Atlanta, GA 30332, USA. 